\title{
The Endosperm Morphology of Rice and its Wild Relatives as Observed by Scanning Electron Microscopy
}

\author{
S. Kasem • D. L. E. Waters • N. F. Rice • F. M. Shapter • \\ R. J. Henry
}

Received: 28 December 2010 / Accepted: 18 April 2011 /Published online: 5 May 2011

(C) Springer Science+Business Media, LLC 2011

\begin{abstract}
While cultivated rice, Oryza sativa, is arguably the world's most important cereal crop, there is little comparative morphological information available for the grain of rice wild relatives. In this study, the endosperm of 16 rice wild relatives were compared to $O$. sativa subspecies indica and $O$. sativa subspecies japonica using scanning electron microscopy. Although the aleurone, starch granules, protein bodies and endosperm cell shapes of the cultivated and non-cultivated species were similar, several differences were observed. The starch granules of some wild species had internal channels that have not been reported in cultivated rice. Oryza longiglumis, Microlaena stipoides and Potamophila parviflora, had an aleurone that was only one-cell thick in contrast to the multiple cell
\end{abstract}

S. Kasem $(\bowtie) \cdot$ N. F. Rice

Grain Foods CRC, Southern Cross University,

PO Box 157, Lismore, NSW 2480, Australia

e-mail: s.kasem.11@scu.edu.au

N. F. Rice

e-mail: nicole.rice@scu.edu.au

D. L. E. Waters $\cdot$ N. F. Rice $\cdot$ F. M. Shapter

Centre for Plant Conservation Genetics,

Southern Cross University,

PO Box 157,

Lismore, NSW 2480, Australia

D. L. E. Waters

e-mail: daniel.waters@scu.edu.au

F. M. Shapter

e-mail: frances.shapter@scu.edu.au

\section{R. J. Henry}

Queensland Alliance for Agriculture and Food Innovation,

The University of Queensland,

Brisbane, QLD 4072, Australia

e-mail: robert.henry@uq.edu.au layers observed in the aleurone of the remaining Oryza species. The similarity of the endosperm morphology of undomesticated species with cultivated rice suggests that some wild species may have similar functional properties. Obtaining a better understanding of the wild rice species grain ultrastructure will assist in identifying potential opportunities for development of these wild species as new cultivated crops or for their inclusion in plant improvement programmes.

Keywords Scanning electron microscope $\cdot$ Rice $\cdot$ Wild rice - Oryza sativa Oryza species $\cdot$ Endosperm $\cdot$ Aleurone

\section{Abbreviations}

SEM Scanning electron microscopy

\section{Introduction}

Cultivated rice, Oryza sativa, belongs to the tribe Oryzeae which consists of 12 genera. In the genus Oryza, there are 22 species of which only two, O. sativa and Oryza glaberrima, are cultivated. The remaining species within the Oryza are commonly designated as wild rices (Vaughan 1994). The Oryza grow in diverse locations and conditions, from the wettest areas in the world to the driest deserts, expanding from $53^{\circ}$ north to $40^{\circ}$ south, from sea level to an altitude of 3,000 $\mathrm{m}$ above sea level (Childs 2004; Juliano 2004). Due to their long history of growing under diversified climatic and environmental conditions, a wide range of diversity exists in the Oryza genus (Childs 2004). This diversity is particularly abundant amongst the wild species which have not undergone human selection (Vaughan 1994). 
Table 1 Wild species of rice studied and their collection record

\begin{tabular}{lll}
\hline Taxon & Plant collection record & Place of collection \\
\hline O. alta & AusTRCF 309269 & Guyana \\
O. australiensis & AusTRCF 309314 & Australia \\
O. glumaepatula & AusTRCF 309281 & Suriname \\
O. grandiglumis & AusTRCF 310560 & Brazil \\
O. nivara/O. sativa $(O$. hybrid) & AusTRCF 309308 & Myanmar \\
O. latifolia & AusTRCF 309288 & Guatemala \\
O. longiglumis & AusTRCF 309291 & Indonesia \\
O. meridionalis & AusTRCF 300119 & Australia \\
O. meyeriana & AusTRCF 309296 & Malaysia \\
O. granulata & AusTRCF 309284 & India \\
O. officinalis & AusTRCF 309302 & Myanmar \\
O. nivara & AusTRCF 309299 & Myanmar \\
O. rufipogon & AusTRCF 309317 & Australia \\
O. spontanea & AusTRCF 309310 & Nepal \\
O. sativa cv. Nipponbare & N/A & Australia \\
O. sativa cv. TeQing & N/A & Australia \\
P. parviflora & AusTRCF 318105 & Australia \\
M. stipoides & AC04-1003504 & Australia \\
\hline
\end{tabular}

Several traits such as resistance to abiotic and biotic stresses have been successfully introgressed from wild species into cultivated rice, resulting in improved cultivated varieties (Vaughan 1994). However, wild species may have potential as new crops in their own right with intrinsically similar starches and functionalities to cultivated rice. Analysis of the functional and nutritional properties of the grain of these 'wild species' is required before they can be considered for commercial use. A previous study on grain morphology of wild species of Oryza (Kasem et al. 2010) reported comparable grain size and shape of wild Oryza to those of cultivated rice. Another study (Shapter et al. 2008) reported similar endosperm morphology of wild species of rice to that of $O$. sativa.

The endosperm plays an important role in determining the nutritional value of rice through its component parts; starch, protein, lipids and fibre (Kang et al. 2006). Starch granule morphology and the physicochemical characteristics of starch influence each other, which in turn affect the total functionality of starch and the procedures that are employed in starch refining (Singh and Kaur 2004). While starch granule shape and size are not the only factors that affect starch performance, they are believed to be a contributing factor to starch functional properties (Singh and Kaur 2004).

Many scanning electron microscope (SEM) investigations of rice starch morphology along with the starch physicochemical properties have been undertaken (Jane et al. 1994; Kang et al. 2006; Sodhi and Singh 2003; Watson and Dikeman 1977), a few of which have been comparative studies of selected wild (mainly Zizania aquatica, $O$. australiensis, O. rufipogon) and cultivated rice starch granules (Hoover et al. 1996; Lorenz 1981; Patindol et al. 2006; Shapter et al. 2008; Wang et al. 2002). Little comparative morphological information is available on a comprehensive set of rice wild relatives.
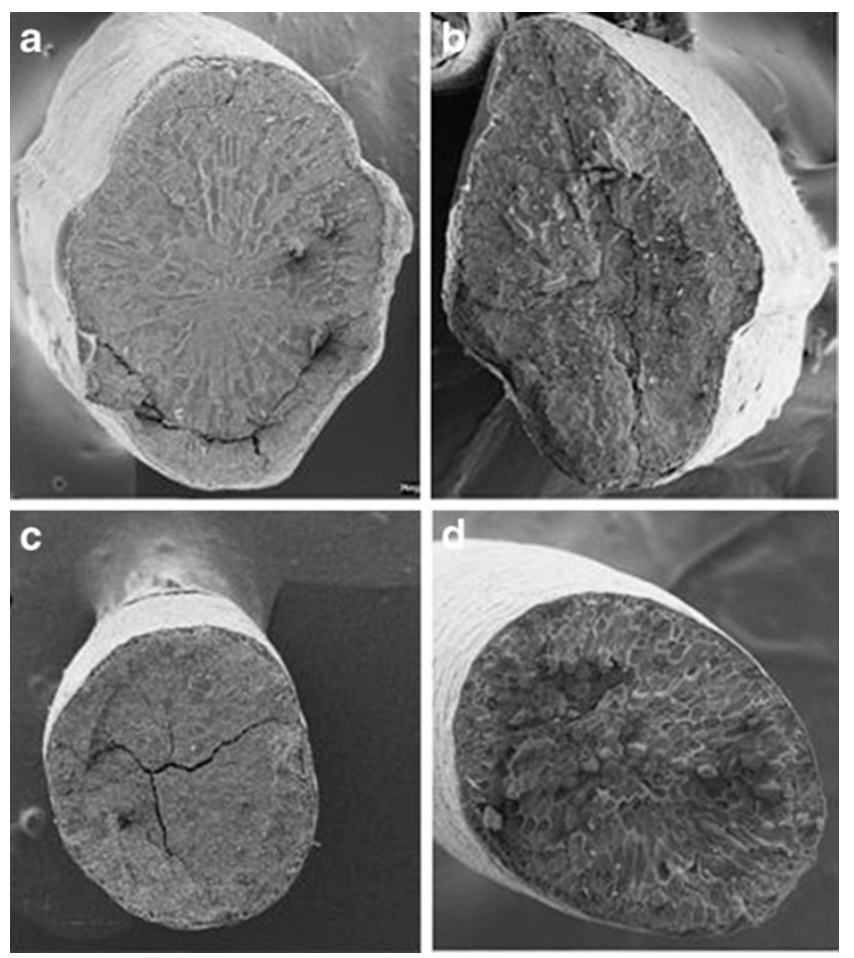

Fig. 1 Representative images of a transverse cross-section of rice and its wild relatives. a $O$. sativa cv. Nipponbare; b $O$. alta, c $O$. longiglumis, $\mathbf{d} M$. stipoides. 
In this study, the aleurone and endosperm of a wide range of wild and cultivated rice grain were compared using scanning electron microscopy. Obtaining a better understanding of wild rice grain ultrastructure will assist in identifying novel wild rice species grain traits and starch properties that could have potential commercial applications.

\section{Materials and methods}

Plant material

Grains of wild Oryza species and Potamophila parviflora were obtained from the Australian Tropical Crops and Forages Collection, Department of Employment, Economic Development and Innovation, Biloela, Australia (http:// www2.dpi.qld.gov.au/, last accessed on 1 July 2010). Oryza hybrid is a cross between Oryza nivara and O. sativa (interim designation used in GRIN for Oryza hybrids which lack an acceptable binomial; http://www.ars-grin.gov/ cgi-bin/npgs/html/taxon.pl?318042, last accessed on 1 July 2010). Microlaena stipoides was sourced from the Australian Plant DNA Bank, Southern Cross University, Lismore,
NSW, Australia. Cultivated Oryza species $O$. sativa cultivar cv. TeQing and $O$. sativa $\mathrm{cv}$. Nipponbare were sourced from Yanco Agricultural Institute, Yanco, NSW, Australia. The list of wild rice species and their collection record appear in Table 1.

\section{Scanning electron microscope}

Grains were manually de-husked and fixed for $24 \mathrm{~h}$ in $10 \%$ formalin. Fixed grains were rinsed three times for $30 \mathrm{~min}$ with distilled water. Rinsed grains were then dehydrated by a standard series of ethanol washes: $25 \%, 50 \%, 75 \%$ and $95 \%$ each for $20 \mathrm{~min}$ and then three washes of $30 \mathrm{~min}$ each in $100 \%$ ethanol. Samples were immediately dried using a Polaron E3100 Critical Point Drier (ProSciTech, Thuringowa, QLD, Australia).

Critical point dried samples, with the exception of $P$. parviflora, were snapped in half transversely using two pairs of forceps. The tiny grain size of $P$. parviflora, precluded this approach so these samples were cut using a scalpel. Halved grains were mounted on aluminium stubs with the fractures facing up. Specimens were gold coated for $30 \mathrm{~s}$ at $35 \mathrm{~mA}$. Images were recorded on a Leo440
Fig. 2 Representative images of aleurone layers in rice and its wild relatives. a Lateral, one-cell thick cubic cell shaped, $O$. latifolia; b ventral, one-cell thick elongated cell shape; $O$. latifolia, c dorsal, two- to threecells thick $O$. glumaepatula, $\mathbf{d}$ dorsal, five-cells thick, $O$. sativa cv. Nippponbare, e subaleurone layer, O. spontanea, $\mathbf{f}$ Testa cell, $O$. alta. $A l$, aleurone layer; $E$, endosperm; $S A L$, subaleurone layer; $T$, testa.
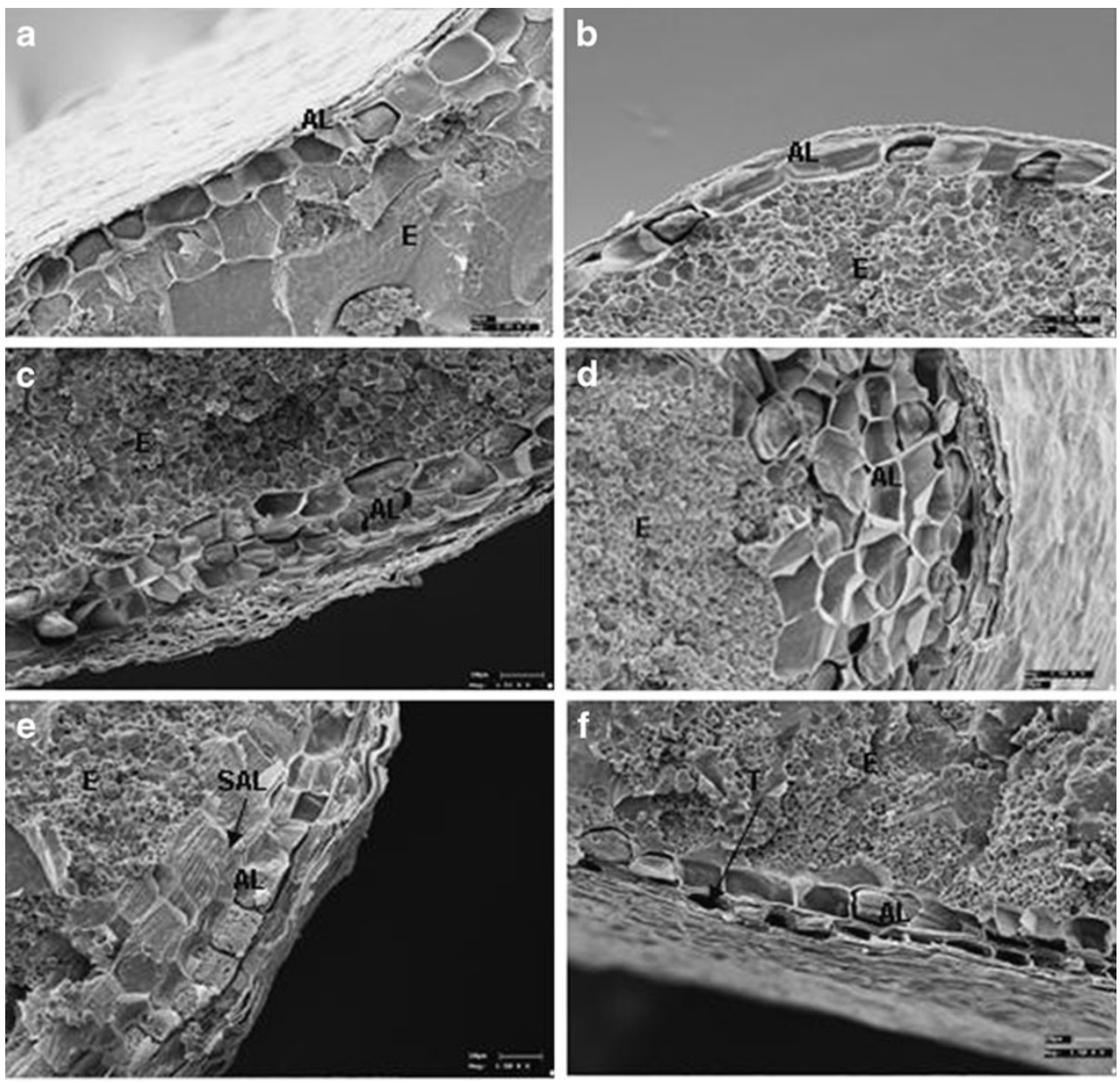
Stereoscan SEM with the probe current at $20 \mathrm{pA}$, EHT at $10.00 \mathrm{kV}$ and a working distance of $15 \mathrm{~mm}$.

\section{Results and discussion}

Transverse sections

Most of the Oryza grain had an undulating perimeter exhibiting up to seven lobes (Figs. 1a and b). In contrast, Oryza longiglumis and the two non-Oryza species ( $P$. parviflora and $M$. stipoides) had simple continuous perimeters without lobes (Figs. 1c and d). Oryza alta, O. nivara, Oryza officinalis, Oryza spontanea, Oryza glumaepatula and $O$. sativa $\mathrm{cv}$. TeQing had similar perimeters with fewer lobes and a narrower ventral side (Fig. 1b) in comparison with $O$. sativa cv. Nipponbare, Oryza hybrid, Oryza granulata, Oryza latifolia, Oryza meyeriana, Oryza meridionalis and Oryza grandiglumis which had more lobes and a wider ventral side (Fig. 1a).

\section{Aleurone, pericarp and testa}

The aleurone surrounds the endosperm, is one to several cells thick depending upon the species, and can influence milling quality (Stone 1996). In accord with previous reports, aleurone cell shape varied between the species studied, as did the number of cells in this layer. Within the Oryza, the number of cells in the aleurone differed from one to five depending on the position either dorsal, ventral or lateral (Fig. 2 and Table 2). The dorsal side usually exhibited more cell layers than the ventral or lateral sides. In O. sativa, up to seven dorsal cell layers have been reported (Watson and Dikeman 1977; Zhou et al. 2002; Juliano 1972), however, we found five dorsal cell layers which is in accord with Wada and Lott (1997). O. meridionalis had a similar number of cells in the aleurone to $O$. sativa cv. Nipponbare while $O$. sativa cv. TeQing, Oryza rufipogon, Oryza australiensis, O. nivara, O. meyeriana and $O$. glumaepatula had three dorsal cell layers suggesting these non-domesticated species may have similar milling properties to cultivated rice. Aluerone cell shapes were not uniform in these species having both elongated and cubic-shaped ventral and lateral cells, while the dorsal cells were always irregular (Table 2).

The aleurone of the one Oryza species, O. longiglumis, and two non-Oryza species, P. parviflora and M. stipoides, were composed of a single cell layer, with uniform cell shapes throughout.

Table 2 Aleurone morphology of rice wild relatives

\begin{tabular}{|c|c|c|c|c|c|c|c|}
\hline Species & $\begin{array}{l}\text { Dorsal cell } \\
\text { thickness }\end{array}$ & $\begin{array}{l}\text { Ventral cell } \\
\text { thickness }\end{array}$ & $\begin{array}{l}\text { Lateral cell } \\
\text { thickness }\end{array}$ & Dorsal cell shape & Ventral cell shape & $\begin{array}{l}\text { Lateral cell } \\
\text { shape }\end{array}$ & $\begin{array}{l}\text { Pericarp } \\
\text { thickness }\end{array}$ \\
\hline $\begin{array}{l}\text { O. sativa } \mathrm{cv} \text {. } \\
\text { Nipponbare }\end{array}$ & 5 & $1-2$ & 1 & Irregular & $\begin{array}{l}\text { Cubic and } \\
\text { elongated }\end{array}$ & $\begin{array}{l}\text { Mostly } \\
\text { elongated }\end{array}$ & thick \\
\hline O. sativa $c v$. TeQing & $2-3$ & 1 & 1 & Irregular & Elongated & & thick \\
\hline $\begin{array}{l}\text { O. nivara/O. sativa } \\
(O . \text { hybrid })\end{array}$ & 3 & 1 & 1 & Irregular & Elongated & $\begin{array}{l}\text { Cubic and } \\
\text { elongated }\end{array}$ & thicker \\
\hline O. nivara & $2-3$ & 1 & 1 & Irregular & Elongated & $\begin{array}{l}\text { Cubic and } \\
\text { elongated }\end{array}$ & \\
\hline O. granulata & 2 & 1 & 1 & Irregular & Elongated & Elongated & thick \\
\hline O. latifolia & $1-2$ & 1 & 1 & Irregular & Elongatedand cubic & Mostly Cubic & thin \\
\hline O. spontanea & 2 & $1-2$ & 1 & Irregular & Elongated & Cubic & \\
\hline O. alta & $1-2$ & 1 & 1 & $\begin{array}{l}\text { Mostly elongated } \\
\text { some cubic }\end{array}$ & Elongated & Elongated & thick \\
\hline O. australiensis & $2-3$ & 1 & 1 & Irregular & $\begin{array}{l}\text { Cubic, elongated } \\
\text { and triangle }\end{array}$ & Cubic & $\begin{array}{c}\text { Thick testa } \\
\text { evident }\end{array}$ \\
\hline O. officinalis & 2 & $1-2$ & 2 & Irregular & Elongated & Elongated & \\
\hline O.rufipogon & 2 & 1 & 2 & Irregular & Cubic & Cubic & \\
\hline O. grandiglumis & $1-2$ & 1 & 1 & Irregular & Elongated & $\begin{array}{l}\text { Mostly } \\
\text { elongated }\end{array}$ & thick \\
\hline O. meyeriana & $2-3$ & 1 & 2 & Irregular & Cubic & Elongated & thick \\
\hline O. glumaepatula & $2-3$ & 1 & 1 & Irregular & Elongated & Elongated & thick \\
\hline O. meridionalis & $3-4$ & $1-2$ & 1 & Irregular & Elongated & Cubic & thick \\
\hline O. longiglumis & 1 & 1 & 1 & Cubic & Cubic & Cubic & thin \\
\hline P. parviflora & $1-2$ & $1-2$ & $1-2$ & Mostly elongated & Mostly elongated & $\begin{array}{l}\text { Mostly } \\
\text { elongated }\end{array}$ & thin \\
\hline M. stipoides & $1-2$ & $1-2$ & $1-2$ & Cubic & Cubic & Cubic & thin \\
\hline
\end{tabular}


For most of the species, no clear subaleurone was evident; however, a distinctive subaleurone was observed in $O$. spontanea and $O$. latifolia (Fig. 2e). The wild relatives of sorghum also have a distinctive subaleurone (Shapter et al. 2009) and it is correlated with high protein in rice (Bechtel and Juliano 1980) and other cereals (Shewry and Morell 2001).
The pericarp and testa had a similar thickness among most of the Oryza and conformed to the typical Gramineae arrangement, being fused together (Stone 1996). However, a clearly visible testa was observed in $O$. alta, $O$. australiensis and $O$. grandiglumis (Fig. 2f). In O. longiglumis and the remaining non-Oryza species, the pericarp and testa appeared more compressed, and therefore thinner than the other Oryza species.
Fig. 3 Representative images of the endosperm of rice wild relatives. a An overview of endosperm from periphery towards central zone, P. parviflora, $\mathbf{b}$ frequent presence of protein bodies at the periphery of endosperm, $O$. grandiglumis, c moderate presence of protein bodies at the zone in between central and periphery of endosperm $O$. grandiglumis, d almost no protein bodies at the centre of endosperm, O. grandiglumis, e spherical and smaller compound granule near to the edge of endosperm, O. granulata, $\mathbf{f}$ compound granules towards the centre of endosperm, O. australiensis, $\mathrm{g}$ compressed compound granules transitioning to angular shape, $O$. grandiglumis, $\mathbf{h}$ compound granules are more intact and angular in the central endosperm, O. glumaepatula. $A L$, aleurone layer; $P E$, endosperm near periphery; $M E$, endosperm between centre and periphery; $S G$, starch granule; $P B$, protein bodies; IN, indentations; $C S G$, intact compound starch granule; $B S G$, broken compound granule.
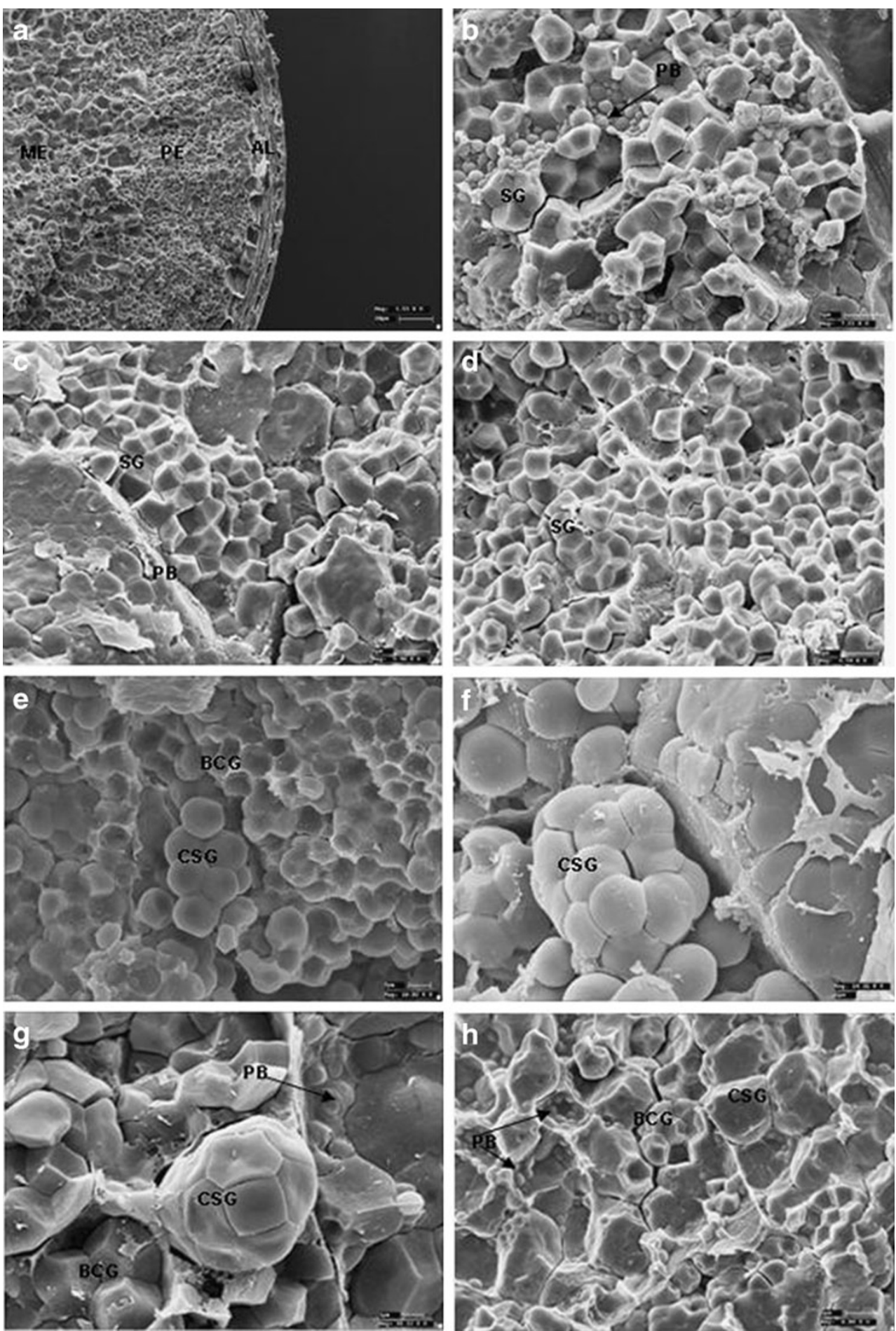
Changes across the endosperm

The endosperm cells maintained a radial orientation consistent with previous reports (Evers and Millar 2002) but their shape varied between elongated and nonelongated. $O$. granulata, O. meyeriana, O. latifolia, $O$. officinalis, O. glumaepatula, O. meridionalis, $O$. sativa cv. TeQing, O. sativa cv. Nipponbare and O. rufipogon, had elongated cells while the endosperm of the remainder of the Oryza and M. stipoides were non-elongated. Dang and Copeland (2004) found the endosperm cells of waxy rice varieties were more elongated than those from the nonwaxy varieties and within the waxy varieties, medium grained waxy varieties had longer cells compared to long grained waxy varieties.

Low numbers of intact endosperm cells were observed in $O$. latifolia, O. meridionalis, O. glumaepatula and $O$. grandiglumis. The spillage of endosperm cell contents commonly observed in these species could be due to the effect of the fracturing process or a soft endosperm and/or less adhesion between starch granules in amyloplasts. Therefore, the lack of intact cells could indicate that these species have softer grains. P. parviflora and O. longiglumis cell shape could not be recorded as no intact endosperm cells were found.

In accord with previous findings (Leesawatwong et al. 2004; Pal et al. 1999), protein bodies occurred most frequently at the periphery when compared to the central endosperm (Figs. 3b-d) in all species. A high concentration of protein bodies at the periphery may mean these grains are less susceptible to breakage during milling (Leesawatwong et al. 2004). Protein bodies of the wild species were of a similar size to that of cultivated rice, generally varying from 0.5 to $2.5 \mu \mathrm{m}$. Most species had both large and small protein bodies embedded in a thin protein matrix. Indentations on compound starch granules due to the presence of protein

Fig. 4 Representative images of starch granules in endosperm of rice wild relatives. a Lenticularshaped starch granule in $O$. latifolia, b spherical-shaped starch granule $O$. meyeriana, c mildly angular starch granule $O$. alta, $\mathbf{d}$ highly angular starch granule M. stipoides, e compressed starch granule $P$. parviflora. $S G$, starch granule; $L S G$, lenticular starch granule; $S S G$, spherical starch granule; $M S G$ mildly angular starch granules; $H S G$, highly angular starch granules; $C M S G$, compressed starch granules; $C W$, cell wall.
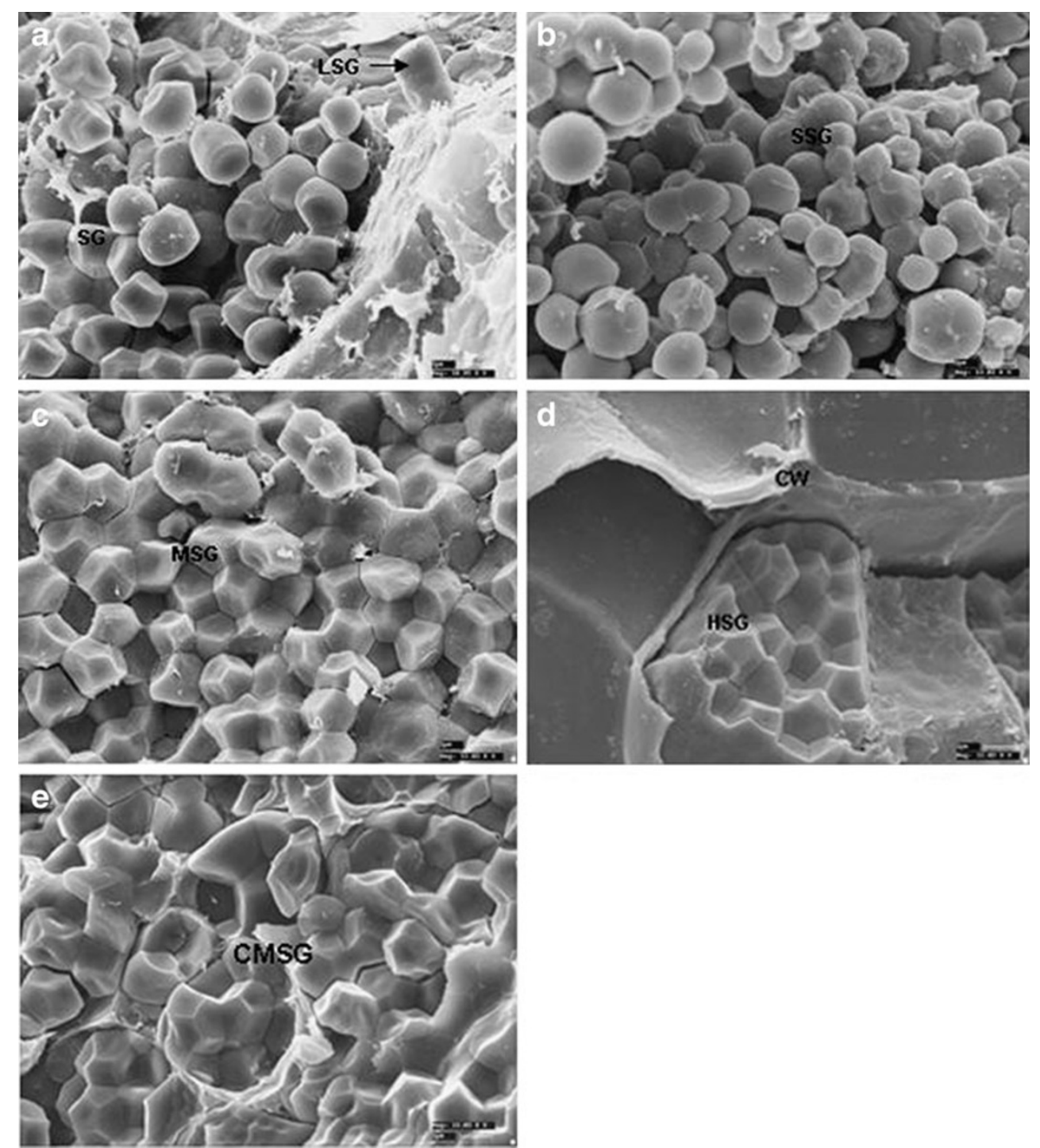
bodies were also observed (Fig. 3h). Protein bodies were visible between starch granules and were spherical or ovoid in shape. Some individual protein bodies were joined to each other by very fine fibrils forming protein body clusters which were then joined by a protein matrix or cell membrane (Fig. 3a).

Visually $O$. australiensis, $O$. meyeriana and $O$. longiglumis exhibited the fewest protein bodies among the Oryza species. Even at the periphery of the endosperm of these species, the presence of protein bodies were almost unnoticeable. Among the cultivated varieties, TeQing exhibited the greatest abundance of protein bodies. Among the wild species, $O$. officinalis had the highest occurrence of protein bodies with a high concentration in the central zone of the endosperm, suggesting this could be a high protein species. P. parviflora exhibited a low frequency of protein bodies throughout the endosperm while none were observed in M. stipoides.

\section{Starch granule size and shape}

The diversity of amyloplast sizes and shapes was such that no clear patterns were evident which would allow the placement of the species into discrete categories. A gradation in the size of compound granules (Fig. 3e-h) was detected from periphery to the centre of the endosperm. The starch granules of both cultivated and wild rice fell in a similar size range of $2-7 \mu \mathrm{m}$. Generally, smaller loosely packed compound granules were found at the periphery of the endosperm while larger, compressed compound granules were towards the centre of the endosperm in all species (Figs. 3e-h). Different sized starch granules were often observed in the same compound granules (Fig. 3h).

In general, starch granules were polygonal with edges that ranged from smooth to highly angular and arranged in compound granules (Figs. 4a-e). Spherical starch granules were usually found at the periphery of the endosperm and they gradually increased in angularity towards the centre. Individual oval or lenticular starch granules were occasionally observed in $O$. australiensis, $O$ latifolia and $O$. sativa cv. TeQing. Both spherical and angular polygonal starch granules were present in $O$. spontanea, $O$. granulata and $O$. hybrid (O. nivara/O. sativa).

The starch granules of $M$. stipoides were polygonal with sharply defined edges (Fig. 4d). Reichert (1913) reasoned that polygonal granules with sharply defined edges were caused by the pressure of numerous starch granules present in the endosperm cells. Earp et al. (2004) suggested tight packing of starch granules in Sorghum bicolor resulted in more sharply edged granules compared with granules that are loosely attached to each other.

O. meyeriana (Fig. 4b) was unique in that it showed spherical starch granules throughout the endosperm. In the compound granules, the individual starch granules were found loosely attached to its neighbouring granules and most of the compound granules were also loosely attached to its neighbouring compound granules. This loose attach-

Fig. 5 Representative images of channels, pinholes and internal cavities in the starch granules of rice wild relatives. a Internal cavities in starch granules, $O$. australiensis, b channels in starch granules, $P$. parviflora, c pin holes on starch granules, $O$. rufipogon. $S G$, starch granule; $C$, channels; $P$, pinholes; $I C$, internal cavities; $P B$, protein bodies.
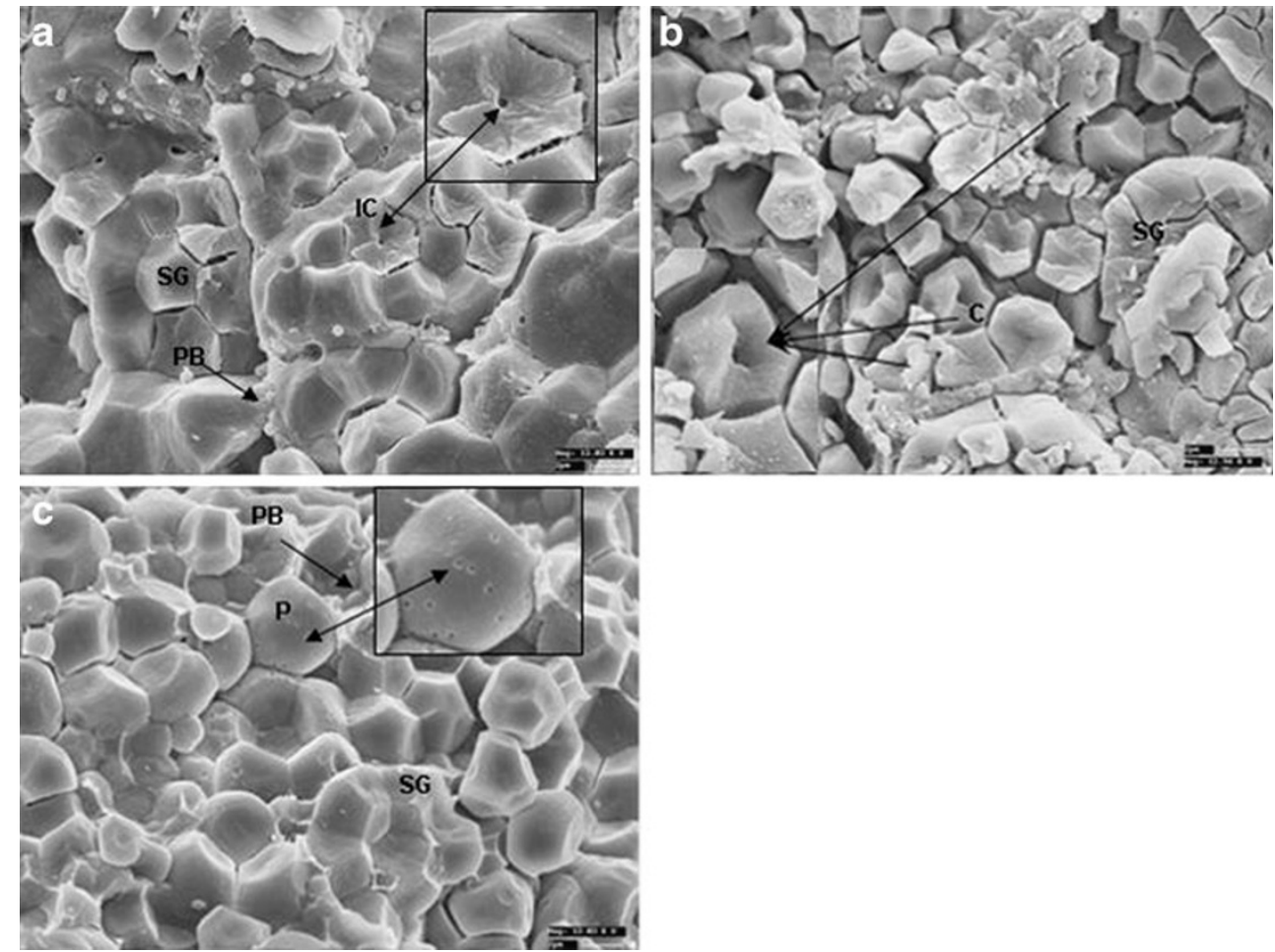
ment may explain why they retained their spherical shape. Some soft wheat varieties have loosely packed starch granules in their endosperm and lower gelatinization temperature than those of hard varieties (Gaines et al. 2000; Zeng et al. 1997).

P. parviflora (Fig. 4e) had starch granules which were unlike those of any other species. The starch granules were compressed with depressions on their lateral sides which may have resulted from pressure from surrounding starch granules.

Starch granule pin holes and channels

Pinholes and channels have been reported in sorghum, barley, oat, corn and millet (Earp and Rooney 1982; Fannon et al. 1992, 2004; Glaring et al. 2006; Shapter et al., 2008) but not rice. Reichert (1913) made a passing reference to 'cavities' in Microlaena and Oryza species but did not clearly describe their appearance. Channels were found in the starch granules of $P$. parviflora and occasionally in $O$. grandiglumis (Fig. 5b). Other Oryza species had internal cavities which were only noticeable when the fracture went through rather than around the starch granule (Fig. 5a). Pin holes across the starch granule surface were observed in $O$. rufipogon, $O$. spontanea, $O$. latifolia and $O$. meyeriana (Fig. 5c).

Pin holes, channels and internal cavities facilitate enzyme susceptibility and chemical reactivity (Fannon et al. 1992) and because of this have a positive impact upon the production of modified starches (Fannon et al. 1992, 1993, 2004). Species with pores, channels and cavities are therefore potential sources of starch which will be amenable to enzyme manipulation for a range of industrial uses. It could be anticipated that the porosity of the starch granules might aid the digestion of these grains in the human or animal gut.

Observations of the grain ultrastructure of the rice wild relatives suggest that these species have potential as human food and/or as sources of starch for industrial use. The aleurone, starch granules and protein bodies were similar to cultivated rice while the pores, channels and internal cavities observed in some species may be desirable for both food uses and modified starch production. Further characterisation of the functional qualities and end use characteristics of these wild species could provide incentives for the development of new rice cultivars in the future.

Acknowledgements We thank Maxine Dawes (School of Environmental Science and Management, Southern Cross University) for her guidance in SEM and the Australian Tropical Crops and Forages Collection, Department of Employment, Economic Development and Innovation (DEEDI), Biloela, Australia (http://www2.dpi.qld.gov.au/ extra/asp/auspgris/) for the grains used in the study. This project was funded by the Grain Foods CRC.

\section{References}

Bechtel DB, Juliano BO. Formation of protein bodies in the starchy endosperm of rice (Oryza sativa L.): a re-investigation. Ann Bot. 1980;45:503-9.

Childs NW. Production and utilization of rice. In: Champagne ET, editor. Rice Chemistry and Technology. St. Paul: American Association of Cereal Chemists, Inc; 2004. p. 1-25.

Dang JMC, Copeland L. Studies of the fracture surface of rice grains using environmental scanning electron microscopy. J Sci Food Agric. 2004;84:707-13.

Earp C, McDonough C, Rooney L. Microscopy of pericarp development in the caryopsis of Sorghum bicolor (L.) Moench. J Cereal Sci. 2004;39:21-7.

Earp C, Rooney L. Scanning electron microscopy of the pericarp and testa of several sorghum varieties. Food Microstructure. 1982;1:125-35.

Evers T, Millar S. Cereal grain structure and development: some implications for quality. J Cereal Sci. 2002;36:261-84.

Fannon JE, Gray JA, Gunawan N, Huber KC, BeMiller JN. Heterogeneity of starch granules and the effect of granule channelization on starch modification. Cellulose. 2004;11:24754.

Fannon JE, Hauber RJ, BeMiller JN. Surface pores of starch granules. Cereal Chem. 1992;69:284-8.

Fannon JE, Shull JM, BeMiller JN. Interior channels of starch granules. Cereal Chem. 1993;70:611-3.

Gaines CS, Raeker MÖ, Tilley M, Finney PL, Wilson JD, Bechtel DB, et al. Associations of starch gel hardness, granule size, waxy allelic expression, thermal pasting, milling quality, and kernel texture of 12 soft wheat cultivars. Cereal Chem. 2000;77:163-8.

Glaring MAG, Koch CBK, Blennow AB. Genotype-specific spatial distribution of starch molecules in the starch granule: A combined CLSM and SEM approach. Biomacromolecules. 2006; 7:2310-20.

Hoover R, Sailaja Y, Sosuiski FW. Characterization of starches from wild and long grain brown rice. Food Res Int. 1996;29:99-107.

Jane J-L, Kasemsuwan T, Leas S, Zobel H, Robyt JF. Anthology of starch granule morphology by scanning Electron. Microscopy Starch. 1994;46:121-9.

Juliano BO. Rice. In: Wrigley C, Croke H, Walker CE, editors. Encyclopedia of grain science. Amsterdam: Elsevier Academic Press; 2004. p. 41-8.

Juliano BO. The rice caryposis and its composition. In: Huston DF (ed) Rice chemistry and technology. St Paul: American Association of Cereal Chemistry, vol 3; 1972. p. 16

Kang HJ, Hwang IK, Kim KS, Choi HC. Comparison of the physicochemical properties and ultrastructure of japonica and indica rice grains. J Agric Food Chem. 2006;54:4833-8.

Kasem S, Waters DLE, Rice N, Shapter FM, Henry RJ. Whole grain morphology of Australian rice species. Plant Genet Resour. 2010;8:74-81.

Leesawatwong M, Jamjod S, Kuo J, Dell B, Rerkasem B. Nitrogen fertilizer alters milling quality and protein distribution in head rice. Proceedings of the 4th International Crop Science Congress: The Regional Institute Ltd; 2004.

Lorenz K. The starch of wild rice (Zizania aquatica). Starch. 1981;33:73-6.

Pal V, Pandey JP, Sah PC. Effect of degree of polish on proximate composition of milled rice. J Food Sci Technol. 1999;36:160-2.

Patindol J, Flowers A, Kuo MI, Wang YJ, Gealy D. Comparison of physicochemical properties and starch structure of red rice and cultivated rice. J Agric Food Chem. 2006;54:2712-8.

Reichert ET. The differentiation and specificity of starches in relation to Genera, species etc. steriochemistry applied to protoplasmic 
processes and products, and as a strictly scientific basis for the classification of plants and animals. Part I. Washington, USA: Carnegie Institution; 1913.

Shapter FM, Henry RJ, Lee LS. Endosperm and starch granule morphoogy in wild cereal relatives. Plant Genetic Resources; 2008. p. 15.

Shapter FM, Dawes MP, Lee LS, Henry RJ. Aleurone and subaleurone morphology in native Australian wild cereal relatives. Aust J Bot. 2009;57:688-96.

Shewry PR, Morell M. Manipulating cereal endosperm structure, development and composition to improve end-use properties Advances in Botanical Research Incorporating Advances in Plant Pathology. London: Academic Press Ltd., 2001. 34:165236.

Singh N, Kaur L. Morphological, thermal, rheological and retrogradation properties of potato starch fractions varying in granule size. J Sci Food Agric. 2004;84:1241-52.

Sodhi NS, Singh N. Morphological, thermal and rheological properties of starches separated from rice cultivars grown in India. Food Chem. 2003;80:99-108.
Stone BA. Cereal Grain Carbohydrate. In: Henry RJ, Kettlewell PS, editors. Cereal grain quality. London: Chapman and Hall; 1996. p. 251-87.

Vaughan DA. The wild relatives of rice. A genetic resources handbook. Manila: International Rice Research Institute; 1994.

Wada T, Lott JNA. Light and electron microscopic and energy dispersive X-ray microanalysis studies of globoids in protein bodies of embryo tissues and the aleurone layer of rice (Oryza sativa L.) grains. Can J Bot Rev Can De Botanique. 1997;75:1137-47.

Wang L, Wang YJ, Porter R. Structures and physicochemical properties of six wild rice starches. J Agric Food Chem. 2002;50:2695-9.

Watson CA, Dikeman E. Structure of the rice grain shown by scanning electron microscopy. Cereal Chem. 1977;54:120-30.

Zeng M, Morris CF, Batey ILW. C.W. Sources of variation for starch gelatinization, pasting and gelation properties in wheat. Cereal Chem. 1997;74:63-71.

Zhou Z, Kevin R, Stuart H, Blanchard C. Composition and functional properties of rice. Int J Food Sci Technol. 2002;37:849-68. 